\title{
Assessment of Knowledge, Attitude, and Practice of Risky Sexual Behavior Leading to HIV and Sexually Transmitted Infections among Egyptian Substance Abusers: A Cross-Sectional Study
}

\author{
Atef Y. Bakhoum, ${ }^{1}$ Max O. Bachmann, ${ }^{1}$ Ehab El Kharrat, ${ }^{2}$ and Remon Talaat ${ }^{3}$ \\ ${ }^{1}$ Norwich Medical School, University of East Anglia, Norwich, UK \\ ${ }^{2}$ Freedom Drugs and HIV Program, Cairo, Egypt \\ ${ }^{3}$ Ipsos Healthcare, 35A Saray El Maadi Tower, Cairo, Egypt \\ Correspondence should be addressed to Atef Y. Bakhoum; atefbakhoum@gmail.com
}

Received 26 December 2013; Revised 17 July 2014; Accepted 17 July 2014; Published 25 August 2014

Academic Editor: Livio Pagano

Copyright (C) 2014 Atef Y. Bakhoum et al. This is an open access article distributed under the Creative Commons Attribution License, which permits unrestricted use, distribution, and reproduction in any medium, provided the original work is properly cited.

\begin{abstract}
Background. Rapidly growing youth population with changing sexual trend in Egypt raised HIV potential. The aim of this study is to assess knowledge, attitude, and practice regarding unsafe sexual behavior among Egyptian drug abusers. Methods. This crosssectional study was conducted in 2008 in the Freedom Drugs and HIV Program on 410 drug abusers in Egypt. Included respondents were subanalyzed by gender, age, education, and intravenous drug usage. Results. KAP average scores on safe sexual behavior were low compared to the maximum possible denoting low awareness and action of drug addicts towards avoidance of infection. Respondents with higher education had significantly better knowledge about safe sexual behavior. Significant positive correlation was shown between age and knowledge of safe sexual behavior. Older age groups were predicted to know more about safe sex, while gender; educational level and intravenous drug usage were not. Similarly, females and intravenous drug users were predicted to have higher attitude for safe sex while age and educational level did not. Conclusion. KAP of safe sexual behavior were low among drug addicts in Egypt increasing potential towards infection with STDs including HIV. The more the age and education level, the better the knowledge towards safe sexual behavior.
\end{abstract}

\section{Introduction}

AIDS was first recognized in United States in summer of 1981, when the U.S. Centers for Disease Control and Prevention (CDC) reported the unexplained occurrence of Pneumocystis carinii pneumonia in five previously healthy homosexual men in Los Angeles and of kaposi sarcoma in 26 previously healthy homosexual men in New York and Los Angeles [1].

Since 2001, the number of people newly infected in the Middle East and North Africa has increased by more than 35\% (from 27000 to 37000 ). Middle East and North Africa were the second most suffering region which experienced significant increases in mortality from AIDS. The limited HIV information available for the Middle East and North Africa indicates that approximately 300000 (250 000$360000)$ people were living with HIV in 2011 compared to 210000 (170 000-270 000) in 2001 [2].
It was 1986 when the first AIDS case patient in Egypt was identified. Egypt was estimated to have 11,000 of PLWHA till the end of 2010, with adults 25-40 years being the majority, and male-female ratio of all detected cases was 4:1 (UNAIDS). According to the Bio-Behavioral Surveillance Survey (BBSS) in 2010 [3], Egypt had a low HIV prevalence $<0.2 \%$ [4], with a concentrated epidemic among men having sex with men (MSM) and intravenous drug users in Cairo and Alexandria [5]. HIV prevalence in most-at-risk groups like MSM populations was estimated at 6.2\% denoting that Egypt may be witnessing a concentrated epidemic among MSM [6].

As per the Egypt-NAP [4], by the end of 2011, there were 4,781 HIV reported cumulative cases (468 new cases detected in 2011 only). Since 1990 and to 2011, there has been a steady increase in the HIV detected cases; that is, number has 
increased from 1,040 cases (from 2001 to 2005) to 1,663 cases (from 2006 to 2009) yet, a population-based survey was never conducted.

Risk behaviors like unprotected sex, multipartnership, no or inconsistence use of condoms, and drug abuse are extremely determinants to health of adolescents and young adults putting them at high risk to HIV and other sexual transmitted infections (STIs) [7]. Wahdan et al. [8] had conducted a study on prevalence of condom use among people living with HIV/AIDS in Egypt that showed a prevalence of condom use of $45.0 \%$ in regular sexual relations while it was only $18.1 \%$ in casual relations. Another study in 2007 [9] conducted in the Nile delta among males aged 15-49 years also confirmed the low use of condoms where only $23.9 \%$ had ever been using condoms, and only a quarter reported knowing how to use condoms properly.

Egyptian MOHP [10, 11] reported that other factors participating in the rapid spread of HIV, for example, more liberal sexual attitude and behavior among the youth (sexual revolution), immigration, and travel, and increased intravenous drug use.

Before formulating public health policies for the prevention of HIV, it is critical to obtain information about the prevalent knowledge, attitude, and practice regarding HIV, other STIs, and sexuality in the target community. Few studies on KAP regarding HIV have been reported from Egypt to address the increased risk of HIV infection $[8,9]$ associated with acquisition of other STIs in addicts. Therefore, the aim of the study is to assess drug addicts' knowledge, attitudes, and practice regarding safe/unsafe sexual behavior risking their infection with HIV and other STIs. We also investigated the impact of age, gender, and educational level and intravenous drug usage on the respondents' KAP of sexual behavior.

\section{Methods}

2.1. Study Area and Design. A cross-sectional study was conducted back in summer and autumn, 2008, in the Freedom Drugs and HIV Program, in male and female addicts' treatment and rehabilitation facilities, which are scattered in 20 facilities all over Egypt. Estimated residents and outreached active addicts were 500-600 individuals at a cross section basis. These facilities provide peaceful place for recovery and allow for support if relapses happen.

2.2. Study Population and Sampling Procedure. There were a total of 500 drug addicts (injecting and noninjecting) in Freedom Program facilities during the study period distributed into the different recovery/treatment/rehabilitation facilities. All the program residents were invited to take part voluntarily where 90 cases were excluded from the major stage; 48 volunteers consented to piloting of questionnaire before the major phase. The pilot phase revealed some careless approaches by the participating addicts resulting in some incomplete answers to the questions and so improvements in techniques were taken in the major phase to insure better gathering of completed answers.
Another 42 addicts were excluded for various reasons, for example, due to uncooperativeness, inconsistency of data, or hugely missing of data.

A total of 410 addicts consented to take part in the major survey and completed the questionnaire. Study included males and females, young and old subjects, urban and rural inhabitants, different socioeconomic classes, and low and high education levels. The biggest number of participants was targeted for this study and so all the resident drug addicts in the facilities, who completed the study questionnaire to the maximum possible, were included in the study.

2.3. Data Collection. The study instrument was a selfadministered questionnaire which comprised fourteen parts. Part-1 was related to respondents' personal sociodemographic background, Part-2 was on marriage and sexual partner, Part-3 was on sexual history (number and criteria of sexual partners), Part-4 was on sexual history with regular sexual partners (if any), Part-5 was on sexual history with CSWs (if any), Part-6 was on sexual history (irregular relationships), Part-7 was on condoms, Part- 8 was on STIs, Part-9 was on HCV and HBV, Part-10 was on knowledge, attitude, practice, and health education to HIV, Part-11 was on knowledge, attitude, practice, and health education to hepatitis virus $B$ and hepatitis virus $C$, Part- 12 was on medical advice seeking-behavior, Part-13 was on sex education and gender issues, and Part-14 was on substance use/misuse and needle sharing behavior. This paper is discussing research findings of the first 7 parts of the survey.

The knowledge, attitude, and practice questionnaire was modified from the instrument used by a survey on HIV knowledge, attitude, and practice adopted from the FHI (Family Health International) questionnaire [6].

As for knowledge on sexual behavior, addicts were asked to respond to 112 statements about safe sexual (as included in the study questionnaire based on FHI questionnaire) behavior. Items were rated on a two-response options: 1: yes, 0: no in 99 statements, while in 13 statements items were rated on a 6-point rating scale (Likert): 0 : not at all to 5: very much. Final scores ranged from 0 to 164 , with high scores suggesting more positive knowledge or more information on safe sex.

As for attitude on sexual behavior, respondents were asked to respond to 95 statements about safe sex (as included in the study questionnaire based on FHI questionnaire). Items were rated on a two-response option: 1 : yes, 0 : no in 80 statements, while in 14 statements items were rated on a 6-point rating scale: 0 : not at all to 5: very much, and in 1 statement items were rated on a 4-point rating scale: 0 : nil to 3: severely. Final scores ranged from 0 to 153 , with high scores suggesting less risky attitude to STIs infection.

As for safe sexual practice, participants were asked to respond to 20 statements about safe sex (as included in the study questionnaire based on FHI questionnaire). Items were rated on a two-response option: 1: yes, 0: no in 17 statements, while in three statements items were rated on a 4-point rating scale: 0: none to 3: each time. Final scores ranged from 0 to 26, with high scores suggesting less risky practices and protection from STIs. 
Higher knowledge scores indicated correct answers to more questions about knowledge. Higher attitude and practice scores meant attitudes and practices that were more towards avoidance of infection.

The English questionnaire was translated into simple Arabic (colloquial) and back-translated into English. Questionnaire was pretested/piloted on a sample of respondents and the results were used to improve the phrasing of questions in the questionnaire.

However the lengthy study tool/questionnaire procedures were strictly taken to keep the highest quality standards in collecting the data from respondents/addicts. This is mainly was in the form of (1) logistically, offering the addicts refreshments during the survey and allowing them to smoke cigarettes to concentrate; (2) though it was a selfadministered survey (except for the illiterate who needed to be interviewed and explained by a literate supervisor oneto-one), research facilitator(s), addicts' supervisors, and even the main study investigator (Dr. Atef Bakhoum) had been in the same room with the respondents while answering the questionnaire in order to keep more discipline, explain a hard question, rephrase it, complete the questionnaire with an impatient addict, or to allow an addict to withdraw and take back his signature on the consent form.

2.4. Data Management and Analysis. During data collection process, the data were checked for completeness and any incomplete or misfiled questions were checked with the respondents for correction. Data were analyzed using SPSS17 statistical software (SPSS Inc. Chicago, 2010). Descriptive statistics were used to give a clear picture of background variables like age, sex, and other variables. The frequency distribution of both dependent and independent variables was worked out. The association between variables was measured and tested using Chi-square or Mann-Whitney test. Mann-Whitney was used in situations involving a categorical independent variable (IV) and an ordinal (rank) dependent variable (DV) while Chi-square was used in situations where both the IV and DV are categorical. $t$-test was used according to type of data. Spearman correlation was used to test the correlation between age and other variables while multivariate regression with odds ratio was used to get an idea on the prediction of KAP scores with age, sex, education, and intravenous drug usage status. $P$ value $<0.05$ was considered significant in all cases.

2.5. Ethical Consideration. Prior to data collection, all study participants were given complete introductory information on the nature of study (supervisors, researchers, and research facilitators). Informed consent forms for voluntary participation in the study with no intimidation or coercion and respect of withdrawal at any time or asking any query, plus proper considering of the participants' privacy, confidentiality, and anonymity, were distributed and had been signed by all participants. Introductory forms and signed informed consent forms were made in English and colloquial Arabic and are being saved in Norwich Medical School, University of East Anglia, UK.

\section{Results}

3.1. Demographics and Sexual History. 410 drug addicts participated voluntarily and completed the questionnaire in The Freedom Program's facilities. The mean age of respondents was $28.63 \pm 6.27$ years and ranged from 16 to 53 years. 361 (88\%) were male. 278 (70\%) had a college degree, university degree, or higher education. 203 (49.5\%) were intravenous drug users.

165 (40.2\%) respondents reported that they have ever been married (Table 1), with mean age at marriage of 24.81 years (range 14-38). However only $26 \%$ reported being currently married versus $64 \%$ who reported being currently unmarried but sexually active.

387 (94\%) respondents reported that they have ever had sex, with mean age at first sexual experience of 17 years (range 6-31). 303 (78\%) reported having sex during the past year. Their mean number of sexual partners during the past year was 2.5 of whom regular sex partners were an average of 1.4 and commercial sex workers were 0.85 , that is, commercial sex workers constituting $1 / 3$ of the sexual partners of respondents over the last year.

$8.5 \%$ of those who had sex during the last year reported having sex with a person of the same sex, that is, $6.3 \%(26 / 410)$ of all respondents. 18 (4.3\% of all respondents) reported having had anal sex during the past 12 months.

During sex with regular sexual partners in the past 12 months, $10(3.3 \%)$ respondents reported using a condom each time, while 100 (33\%) reported never using a condom (Table 2), with the commonest reasons being "because they did not like it," 57 (52.8\%).

With a close focus on females compared to males, female addicts were significantly younger (mean age was 26.1 versus 28.9 years for males) and less likely to have ever been to school (less educated) (91.8\% versus $97.2 \%$ of males) $(P$ value (chi square test) < 0.05 ) where only $57 \%$ had college degree or university degree versus $71 \%$ of males. Females were statistically significant to be more likely to have been married, in general (67\% versus $37 \%$ of males). Those who had been married, they married at younger ages (average of 19.02 years old $)$ than men did $(26.28$ years old $)$. ( $P$ value $(t$ test $)<0.05)$.

\subsection{Knowledge, Attitude, and Practice (KAP) of Safe Sexual} Behavior. In order to identify the total knowledge, attitude, and practice scores of participants for safe sex, each respondent was asked to respond to number of statements about safe sex (as included in the study questionnaire based on FHI questionnaire) and then items were rated on a scoring system to get the final score, with high scores suggesting less risky practices and protection from STIs.

Respondents under the study had shown fair knowledge and attitude towards safe sex while they had poor practice as shown by the KAP scores stating higher knowledge scores than attitude and practice scores. In general, scores tended to be of low mean values (Table 3), compared to the maximum possible showing to what extent KAP of respondents towards safe sex was not up to the desirable standard. In order to better understand these scores, further analysis was done by gender (males versus females), education level (high versus 
TABLE 1: Sample characteristics and sexual history.

\begin{tabular}{|c|c|}
\hline$\overline{\text { Sex }}$ & \\
\hline Male, $n(\%)$ & $361(88.0 \%)$ \\
\hline Female, $n(\%)$ & $49(12.0 \%)$ \\
\hline Age & \\
\hline$N$ & 374 \\
\hline Mean (SD) & $28.63(6.27)$ \\
\hline Min.-Max. & $16-53$ \\
\hline $\begin{array}{l}\text { If ever gone to school, what is the highest } \\
\text { qualification you have? }\end{array}$ & \\
\hline Primary, $n(\%)$ & $17(4.3 \%)$ \\
\hline Preparatory, $n(\%)$ & $17(4.3 \%)$ \\
\hline Vocational, $n(\%)$ & $38(9.7 \%)$ \\
\hline Secondary, $n(\%)$ & $39(9.9 \%)$ \\
\hline College or institute, $n(\%)$ & $48(12.2 \%)$ \\
\hline University or higher, $n(\%)$ & $230(58.5 \%)$ \\
\hline No answer, $n(\%)$ & $4(1.0 \%)$ \\
\hline Intravenous drug usage (IVDU) & \\
\hline IVDUs, $n(\%)$ & $203(49.5 \%)$ \\
\hline Non-IVDU, $n(\%)$ & $207(50.5 \%)$ \\
\hline Have you ever been married? & \\
\hline Yes, $n(\%)$ & $165(40.2 \%)$ \\
\hline No, $n(\%)$ & $239(58.3 \%)$ \\
\hline No answer, $n(\%)$ & $6(1.5 \%)$ \\
\hline $\begin{array}{l}\text { If married, } \\
\text { how old were you when you first married? }\end{array}$ & \\
\hline$N$ & 165 \\
\hline Mean (SD) & $24.81(5.0)$ \\
\hline Min.-Max. & $14-38$ \\
\hline $\begin{array}{l}\text { What describes your current marital/sexual activity } \\
\text { status? }\end{array}$ & \\
\hline $\begin{array}{l}\text { Married and having sex with my wife/husband, } n \\
\text { (\%) }\end{array}$ & $85(20.7 \%)$ \\
\hline $\begin{array}{l}\text { Married and having sex with another } \\
\text { woman/man, } n(\%)\end{array}$ & $14(3.4 \%)$ \\
\hline Married and not having sex with someone, $n(\%)$ & $8(2.0 \%)$ \\
\hline $\begin{array}{l}\text { Unmarried and having sex with a woman/man, } \\
n(\%)\end{array}$ & $134(32.7 \%)$ \\
\hline $\begin{array}{l}\text { Unmarried and not having sex with someone } \\
n(\%)\end{array}$ & $129(31.5 \%)$ \\
\hline No answer, $n(\%)$ & $40(9.8 \%)$ \\
\hline $\begin{array}{l}\text { Have you ever had a sexual relationship before? (sex } \\
\text { means vaginal or rectal sex) }\end{array}$ & \\
\hline Yes, $n(\%)$ & $387(94.39 \%)$ \\
\hline No, $n(\%)$ & $22(5.37 \%)$ \\
\hline No answer, $n(\%)$ & $1(0.24 \%)$ \\
\hline How old were you when you first had sex? & \\
\hline$N$ & 297 \\
\hline Mean (SD) & $16.89(3.5)$ \\
\hline Min.-Max. & $6-31$ \\
\hline Don't know, $n(\%)$ & $70(23.6 \%)$ \\
\hline No answer, $n(\%)$ & $20(6.7 \%)$ \\
\hline Have you had sex within the past 12 months? & \\
\hline Yes, $n(\%)$ & $303(78.29 \%)$ \\
\hline No, $n(\%)$ & $67(17.31 \%)$ \\
\hline Don't know, $n(\%)$ & $7(1.81 \%)$ \\
\hline No answer, $n(\%)$ & $10(2.58 \%)$ \\
\hline
\end{tabular}

TABLE 1: Continued.

In total, do you know how many were they in the past 12 months?

$\begin{array}{lc}N & 202 \\ \text { Mean (SD) } & 2.5(2.3) \\ \text { Min.-Max. } & 0-24 \\ \text { Don't know, } n(\%) & 65(32.17 \%) \\ \text { No answer } & 36(17.82 \%)\end{array}$

In those past 12 months, how many of them were regular sex partners, for example, as your wife/girl friend or husband/boyfriend or anybody else without money for sex?

N

Mean (SD)

Min.-Max.

1-3 regular partners

4-6 regular partners

7-9 regular partners

Don't know, $n$ (\%)

$36(17.82 \%)$

In those past 12 months how many of them were commercial sex workers?

N

Mean (SD)

$0.85(1.83)$

Min.-Max.

$0-17$

1-3 CSWs

$115(66 \%)$

$21(12 \%)$

$1(1 \%)$

7-9 CSWs

10 or more CSWs

$33(19 \%)$

In the past 12 months, how many of those irregular sex partners have you never lived with except with money for sex?

N

Mean (SD)

171

Min.-Max.

Don't know, $n$ (\%)

$1.22(1.84)$

$0-12$

$47(27.48 \%)$

We talked about having sex with people from the other sex; now, have you ever had sex with a person of the same sex?

$\begin{array}{lc}\text { Yes, } n(\%) & 70(18.08 \%) \\ \text { No, } n(\%) & 164(42.37 \%) \\ \text { No answer, } n(\%) & 153(39.53 \%)\end{array}$

Have you had sex with a person of your same sex, within the past 12 months?

Yes, $n(\%)$

$26(8.58 \%)$

No, $n(\%)$

$91(30.03 \%)$

No answer, $n$ (\%)

$186(61.38 \%)$

Have you had anal sex in the past 12 months?

Yes, $n(\%)$

$18(69.27 \%)$

No, $n(\%)$

$5(19.23 \%)$

Don't know, $n$ (\%) 
TABle 2: Condom usage.

\begin{tabular}{llc}
\hline & Each time, $n(\%)$ & $10(3.3 \%)$ \\
In the past 12 months, how & $\begin{array}{l}\text { Almost every time, } \\
\text { would you describe your }\end{array}$ & $6(2.0 \%)$ \\
practice for using condoms? & Sometimes, $n(\%)$ & $39(12.9 \%)$ \\
& Never, $n(\%)$ & $100(33.0 \%)$ \\
& Don't know, $n(\%)$ & $2(0.7 \%)$ \\
& No answer, $n(\%)$ & $146(48.2 \%)$ \\
\hline \multicolumn{4}{c}{ Why didn't you use a condom this time? } \\
I don't like it & Yes, $n(\%)$ & $57(52.8 \%)$ \\
I didn't think of it & Yes, $n(\%)$ & $38(35.5 \%)$ \\
We used other contraceptive & Yes, $n(\%)$ & $33(31.1 \%)$ \\
measures & Yes, $n(\%)$ & $28(26.2 \%)$ \\
I didn't think it was important & Yes, $n(\%)$ & $17(15.6 \%)$ \\
No answer & Yes, $n(\%)$ & $14(13.6 \%)$ \\
Other, mention & Yes, $n(\%)$ & $5(4.7 \%)$ \\
Partner refused & Yes, $n(\%)$ & $4(3.8 \%)$ \\
Don't know & Yes, $n(\%)$ & $1(1.0 \%)$ \\
Wasn't available &
\end{tabular}

TABLE 3: KAP scores of sexual behavior in overall sample.

\begin{tabular}{lccc}
\hline Cases & \multicolumn{3}{c}{ Safe sexual behavior } \\
& Knowledge & Attitude & Practice \\
\hline Mean & 70.1 & 54.3 & 3.7 \\
Min. & 0 & 0 & 0 \\
Maximum & 149 & 99 & 23 \\
Poor & $90(22 \%)$ & $64(15.6 \%)$ & $348(84.9 \%)$ \\
Fair & $278(67.8 \%)$ & $235(57.3 \%)$ & $55(13.4 \%)$ \\
Good & $42(10.2 \%)$ & $111(27.1 \%)$ & $7(1.7 \%)$ \\
\hline
\end{tabular}

low education), and intravenous drug usage (injectors versus noninjectors) (Table 4).

No significant differences in the knowledge, attitude, and practice scores for sexual behavior were found between males and females or between Injectors and noninjectors; that is, gender and drug injection were not determining factors in KAP about safe sex ( $P$ value (Mann Whitney test $)>0.05$ ). With regard to education, respondents with above university education had significantly higher scores for knowledge about safe sexual behavior than those with below university education $(P$ value $($ Mann Whitney test $)<0.05)$. Other attitude and practice scores did not differ significantly with education level.

A significant (weak) positive correlation (Spearman $R$ coefficient is 0.170 ) was shown between age and knowledge of safe sexual behavior $(P$ value $<0.05)$; that is, the more the addicts grew older the more their proper knowledge about safe sexual behavior was. Still, getting older did not affect the attitude or practice towards safe sex (Table 5).

Trying to associate the KAP scores with gender, educational level, and intravenous drug usage (Table 6), females, higher education students were more likely to have higher knowledge than males, lower education students while noninjectors had higher practice scores than injectors $(P$ value $<$ $0.05)$.

Our study showed that $94-98 \%$ of respondents who participated in the survey had heard about STIs, HIV, HCV, and HBV.

\section{Discussion}

Generally speaking, average knowledge, attitude, and practice (KAP) scores were low denoting the low knowledge, attitude, and practice towards safe sex procedures/behavior. The total mean score of knowledge was 70.1 (range 0-149); attitude was 54.3 (range 0-99) while practice was 3.7 (range $0-23$ ), among addicts. Our study showed no significant differences in the knowledge, attitude, and practice scores for sexual behavior between males and females; that is, the overall behavior status of participants was not statistically influenced by gender. In line with our findings there was a research in Ethiopia by Shiferaw et al. in 2011 [12], while in contrast to our findings, there was a study in India which indicated that good knowledge was observed in males compared to females [13]. This discrepancy might be due to cultural differences where females in India might have had more social restrictions than males of the same age, which was not observed in our study, leading to lower knowledge scores in females in their study compared to us.

With consideration to education, those with university degree (higher education level) had better knowledge on sexual behavior (mean rank of 229.526 versus 174.800 ) but their attitude and practice did not significantly differ from those with lower education level. Education might lead to better knowledge on safe sex. Our finding emphasised the need to improve the role of teachers in HIV awareness programs. This is important because educating school children about safe sex is one of the most crucial ways of postponing the onset of sexual activity among them [14]. Intervention programs providing sex education had been reported to result in a marked improvement in the knowledge of attendees about HIV and have been associated with a positive change in their attitude towards the disease [15].

This discrepancy between knowledge scores on one side and attitude and practice scores on the other side was not surprising; similar findings have been reported from developed countries [16].

Our results showed positive correlation between age and knowledge of safe sexual behavior which meant the more the addicts grew older the more their knowledge about safe sex was. Still knowledge was not translated into better attitude or practice.

Another interesting finding in our study was that $94-98 \%$ of respondents participated in the survey had heard about STIs (sexually transmitted infections), that is, HIV, HBV, and HCV. This was an encouraging finding which should further be strengthened by establishing educational seminars on HIV. It is very important to link this finding in addicts (and general population) minds with the safe sexual practices. People in Egypt should be aware that STIs including HIV, HBV, and $\mathrm{HCV}$ are very linked to poor sexual practices. 


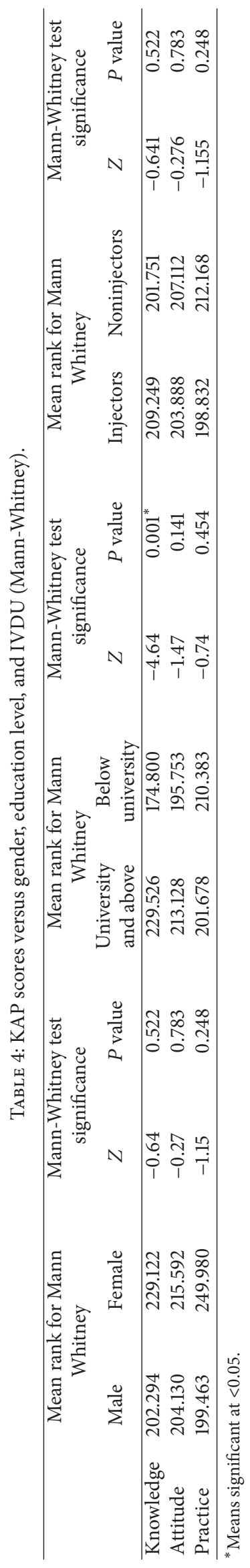


TABLE 5: Correlation between age and knowledge, attitude, and practice to sexual practice scores.

\begin{tabular}{lcc}
\hline & Age versus & \\
& Spearman $R$ & $P$ value \\
\hline Knowledge (sexual practice) & 0.170 & $0.001^{*}$ \\
Attitude (sexual practice) & 0.032 & 0.531 \\
Practice (sexual practice) & -0.069 & 0.181 \\
\hline
\end{tabular}

${ }^{*}$ Means significant at $<0.05$.

TABLE 6: KAP scores versus gender, education level, and IVDU.

\begin{tabular}{|c|c|c|c|}
\hline & Average (SD) of knowledge & Average (SD) of attitude & Average (SD) of practice \\
\hline \multicolumn{4}{|l|}{ Gender } \\
\hline Female & $74.97(21.24)$ & $56.16(20.22)$ & $5.22(4.92)$ \\
\hline Male & $69.47(26.46)$ & $54.06(20.28)$ & $3.44(4.22)$ \\
\hline$P$ value & $0.042^{*}$ & 0.435 & 0.96 \\
\hline \multicolumn{4}{|l|}{ Education } \\
\hline Below university & $63.71(25.78)$ & $52.64(20.53)$ & $3.89(4.54)$ \\
\hline University and above & $75.15(24.98)$ & $55.62(19.99)$ & $3.47(4.19)$ \\
\hline$P$ value & $0.045^{*}$ & 0.301 & 0.678 \\
\hline \multicolumn{4}{|l|}{ Injection } \\
\hline IVDU & $70.81(25.54)$ & $54.16(19.73)$ & $3.26(3.94)$ \\
\hline Non-IVDU & $69.44(26.37)$ & $54.46(20.81)$ & $4.04(4.69)$ \\
\hline$P$ value & 0.153 & 0.864 & $0.014^{*}$ \\
\hline
\end{tabular}

${ }^{*}$ Means significant at $<0.05$.

Our study suggested that the education system needs to implement specific and focused educational programs for students in school prior to college admission and to promote health promotion. It is important that school students understand STIs (including HIV, HCV, and HBV) prevention, and transmission, as well as developing positive attitude and safe sex practice. The school is an appropriate place and time to have educational programs that address healthy sexual attitudes, for example, abstinence till marriage, delay onset of first sexual intercourse, and negotiate safer sexual practices.

Our study also suggested that more efforts need to be made to educate addicts in Egypt about safe sexual practices with consideration to its main correlation with HIV/AIDS and other STIs. Policy makers should be made aware that if this trend towards having more sexual partners continued, the potential for HIV to be spread through heterosexual sex will definitely increase. Condom use should be promoted, especially among the sexually active youth with multiple sexual partners, as well as studies conducted to introduce sex education to increase condom use $[17,18]$ as well as decrease sexual intercourse associated to alcohol or drugs [19].

Figures regarding the variety of sexual risky behaviors and the variety of factors involved in the performance of preventive sexual behaviors increase the importance of implementing programs and campaigns that aim specifically to change behaviors and promoting sexual and reproductive health $[20,21]$.

In order to fully understand an addict, one has to consider the individual family contexts where the addict interacts as well as the ways individuals organize sexual experiences. This means that the way addicts relate sexually to others is deeply influenced by family and social models.

\section{Study Limitations}

Our study was confronted by multiple limitations, for example, the sample was not random and so there might be a difficulty to generalize these results; however this can defended by the diversity of respondents included from 20 facilities nationwide in Egypt (males and females, young and old subjects, urban and rural inhabitants, different socioeconomic classes, and low and high education levels). Also among limitations is no inclusion of subjects outside rehabilitation centers and this is defended by the fact that some outreach addicts were included in the study. Also the study subjects were under rehabilitation; however these freedom facilities are for treatment as well as rehabilitation of addicts and hence some respondents were actually under treatment. Time and budget constraints were among the most important limitations in this study; in addition it is very difficult in a Muslim conservative country like Egypt to reach such a high number of addicts, MSMs (men having sex with men) and CSWs (commercial sex workers) unless you can reach them via specialized centers like the freedom facilities.

\section{Conclusion and Recommendations}

In our cross-sectional survey of drug addicts in the Freedom Drugs and Rehabilitation Program's facilities in Egypt, awareness/knowledge of STIs and HIV in relation to sexual 
behavior was better than attitude and practice. Older age groups and those with higher education tended to have better awareness/knowledge about these STIs.

Therefore, our study urges continued and strengthened drug rehabilitation and health education to bring a positive change in knowledge and hence attitude and practice, for safer sex to protect from threat of infection by STIs and HIV in Egypt.

Education might have played a major role in lowering the dissemination of HIV and other STIs.

\section{Ethical Approval}

This paper receives an ethical approval from the Freedom Program Prevention, Treatment and Rehabilitation of Drugs and AIDS Research Ethics Committee, Egypt.

\section{Disclosure}

Max O. Bachmann and Ehab El Kharrat are coauthors.

\section{Conflict of Interests}

The authors declare that there is no conflict of interests regarding the publication of this paper.

\section{Acknowledgments}

The authors acknowledge the Founder and President, Programs Heads, Sector Managers, Hostel Managers, and Supervisors in the Freedom Drugs and HIV Program for their kind efforts in facilitating a safe, organized, and quite environment to conduct this study. They also acknowledge the research facilitators for their efforts with observing and note-taking. They are also so grateful to the individuals who kindly volunteered to participate in this study and give their time, effort, and trust.

\section{References}

[1] A. S. Fauci, "The AIDS epidemic-considerations for the 21st century," The New England Journal of Medicine, vol. 341, no. 14, pp. 1046-1050, 1999.

[2] UNAIDS, Report on the Global AIDS Epidemic, UNAIDS, Geneva, Switzerland, 2012.

[3] Ministry of Health Egypt, HIV/AIDS Biological and Behavioral Surveillance Survey: Summary Report, National AIDS Programme, Cairo, Egypt, 2010.

[4] Egypt-NAP data, 2010 and 2011.

[5] UNGASS, GLOBAL AIDS Response Progress Report, 2012.

[6] HIV/AIDS Biological \& Behavioral Surveillance Survey, Summary, National AIDS Program Egypt, 2006.

[7] G. Abebe and A. Fekadu, "A health concerns and challenges among high school adolescents," Ethiopian Journal of Health Development, vol. 10, no. 1, pp. 37-40, 2000.

[8] I. Wahdan, A. Wahdan, M. El Gueneidy, and I. Abd El Rahman, "Prevalence and determinants of condom utilization among people living with HIV/AIDS in Egypt," Eastern Mediterranean Health Journal, vol. 19, no. 12, 2013.
[9] I. A. Kabbash, N. M. El-Sayed, A. N. Al-Nawawy, I. K. Shady, and M. S. Abou Zeid, "Condom use among males (15-49 years) in lower Egypt: knowledge, attitudes and patterns of use," Eastern Mediterranean Health Journal, vol. 13, no. 6, pp. 14051416, 2007.

[10] "Ministry of Health and Population takes to the rails to promote awareness for HIV/AIDS," The Daily Star-Egypt Edition, December 2006.

[11] Egyptian Ministry of Health and Population, Bio-Behavioral Serveillance Surveys, 2007.

[12] Y. Shiferaw, A. Alemu, A. Girma et al., "Assessment of knowledge, attitude and risk behaviors towards HIV/AIDS and other sexual transmitted infection among preparatory students of Gondar town, north west Ethiopia," BMC Research Notes, vol. 4, article 505, 2011.

[13] S. S. Lal, R. S. Vasan, P. S. Sarma, and K. R. Thankappan, "Knowledge and attitude of college students in Kerala towards HIV/AIDS, sexually transmitted diseases and sexuality," National Medical Journal of India, vol. 13, no. 5, pp. 231-236, 2000.

[14] R. Short, “Teaching safe sex in school," International Journal of Gynecology \& Obstetrics, vol. 63, supplement 1, pp. S147-S150, 1998.

[15] H. K. Agrawal, R. S. P. Rao, S. Chandrashekar, and J. B. S. Coulter, "Knowledge of and attitudes to HIV/AIDS of senior secondary school pupils and trainee teachers in Udupi District, Karnataka, India," Annals of Tropical Paediatrics, vol. 19, no. 2, pp. 143-149, 1999.

[16] N. E. MacDonald, G. A. Wells, W. A. Fisher et al., "High-risk STD/HIV behavior among college students," The Journal of the American Medical Association, vol. 263, no. 23, pp. 3155-3159, 1990.

[17] D. B. Kirby, B. A. Laris, and L. A. Rolleri, "Sex and HIV education programs: their impact on sexual behaviors of young people throughout the world," Journal of Adolescent Health, vol. 40, no. 3, pp. 206-217, 2007.

[18] T. E. Mueller, L. E. Gavin, and A. Kulkarni, "The association between sex education and youth's engagement in sexual intercourse, age at first intercourse, and birth control use at first sexual intercourse," Journal of Adolescent Health, vol. 42, no. 1, pp. 89-96, 2008.

[19] A. S. Madkour, T. Farhat, C. T. Halpern, E. Godeau, and S. N. Gabhainn, "Early adolescent sexual initiation as a problem behavior: a comparative study of five nations," Journal of Adolescent Health, vol. 47, no. 4, pp. 389-398, 2010.

[20] M. G. Matos, Ed., Sexualidade, Segurança e SIDA, Sexuality, Safetiness and AIDS, IHMT/FMH/FCT, Lisbon, Portugal, 2008.

[21] M. G. Matos, C. Simões, G. Tomé et al., "A Saúde dos Adolescentes Portugueses-Relatório do Estudo HBSC 2010," The Health of Portuguese Adolescents-HBSC Study Report, 2011, ACS/FMH/UTL/CMDT-UNL. 


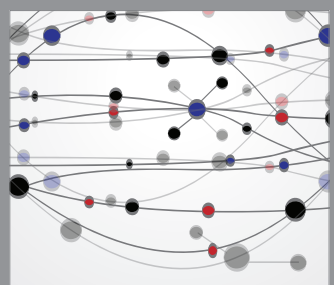

The Scientific World Journal
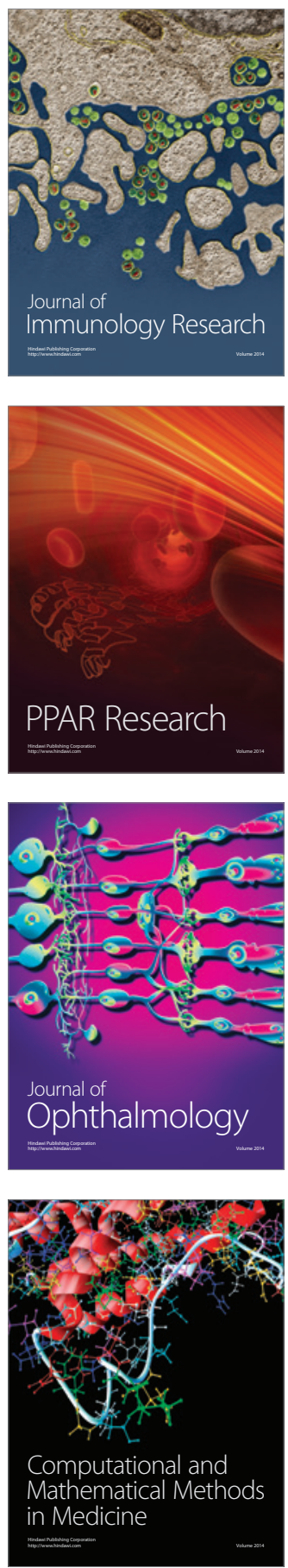

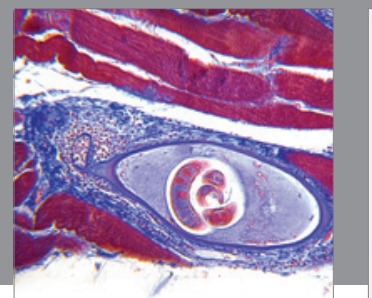

Gastroenterology

Research and Practice
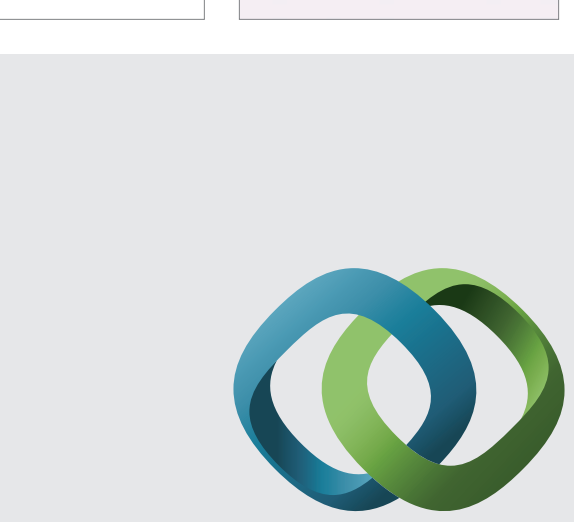

\section{Hindawi}

Submit your manuscripts at

http://www.hindawi.com
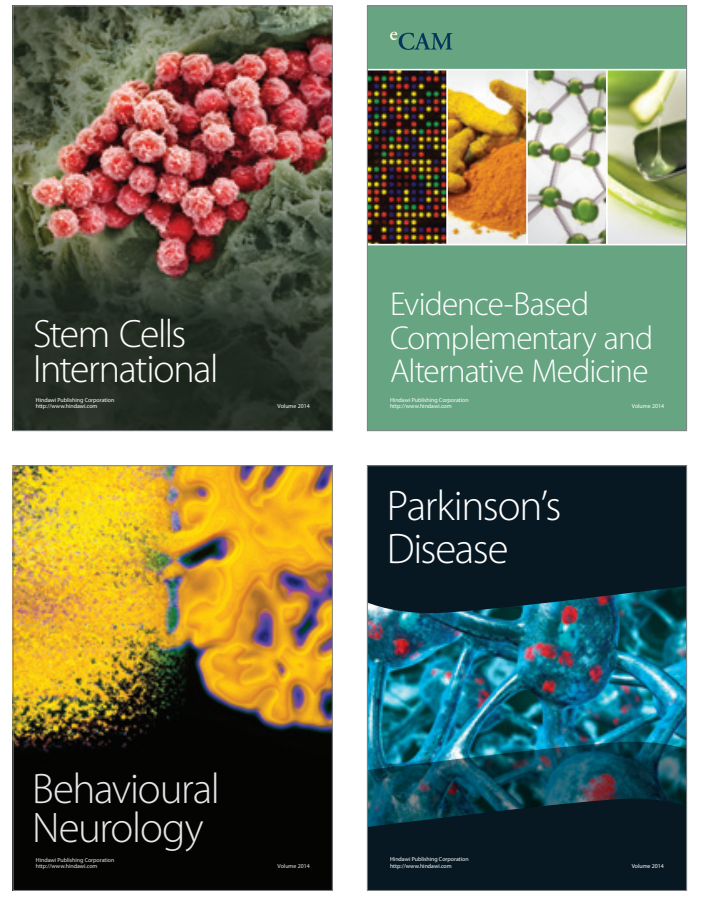
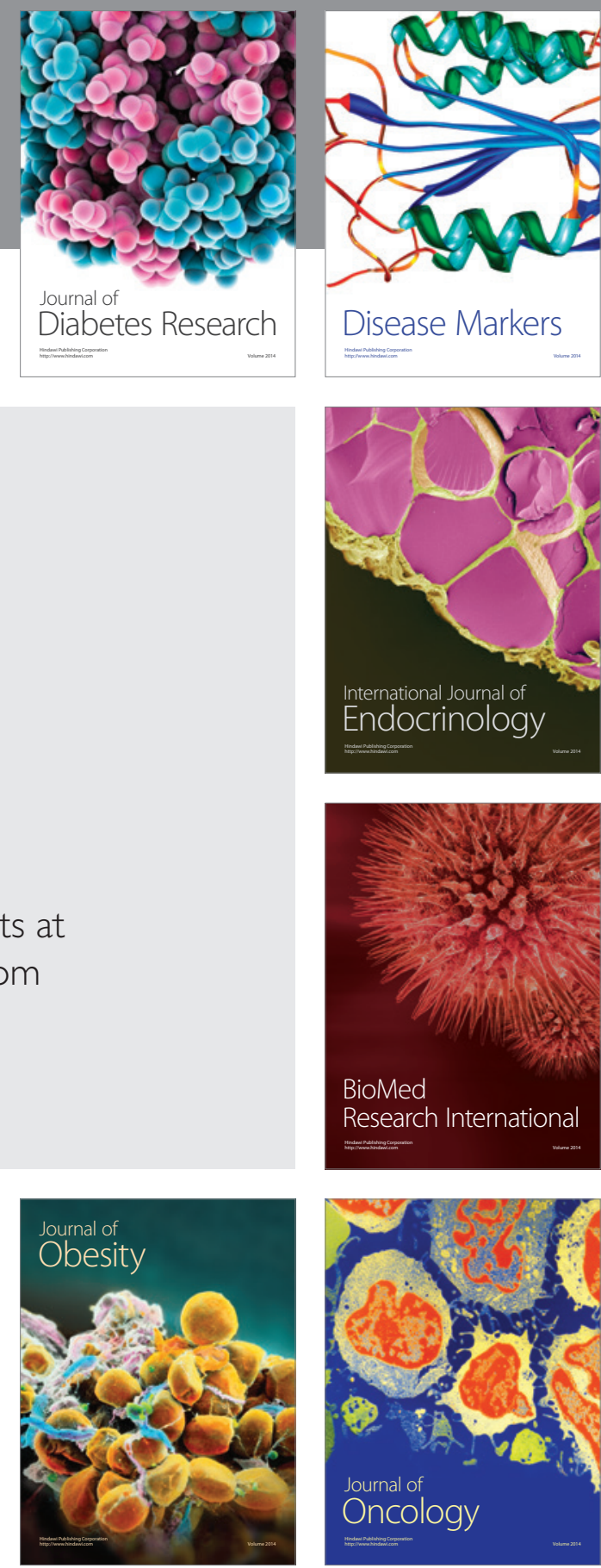

Disease Markers
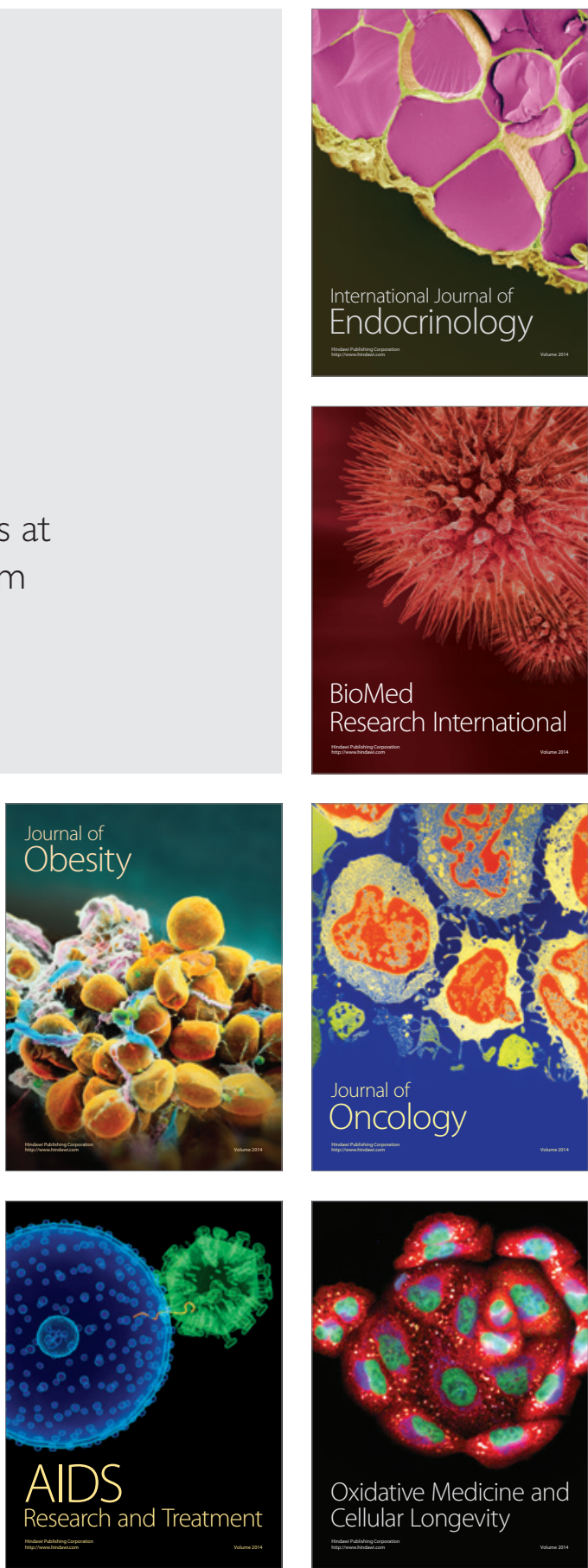